\title{
CONFINAR A EXPERIÊNCIA ESCOLAR NUM ECRÃ?
}

\author{
CONFINE THE SCHOOL EXPERIENCE ON A SCREEN?
}

¿CONFINAR LA EXPERIENCIA ESCOLAR EN UNA PANTALLA?

\author{
Licínio Carlos Viana da Silva Lima ${ }^{1}$ (D) \\ IVANY RODRIGUES PINO² \\ Theresa AdriÃO ${ }^{3}$ \\ Luana Costa Almeida ${ }^{4}$ \\ Celso João Ferretti ${ }^{5}$ \\ Antonio Álvaro Soares Zuin ${ }^{6}$ \\ Sandra Maria Zákia Lian SouZa ${ }^{7}$ \\ Pedro Goergen ${ }^{8}$ \\ Carmen Sylvia Vidigal Moraes ${ }^{9}$ \\ Adriana Dragone Silveira ${ }^{10}$ \\ SALOMÃo Barros Ximenes ${ }^{11}$ (iD \\ XAVIER RAMBLA ${ }^{12}$
}

A

educação escolar foi, historicamente, confinada numa sala de aula, a partir de uma tecnologia multissecular: o ensino em classe, capaz de ensinar a todos como se fossem um só, desenvolvido de maneira organizada nos colégios dos Jesuítas. O projeto de uma educação escolar em larga escala baseou-se nessa tecnologia e numa outra, ainda de mais vasto alcance: a imprensa de Gutenberg e o consequente livro impresso. Foi o que permitiu a Coménio (1976), na sua Didáctica Magna, prometer ensinar tudo a todos e em todos os lugares.

Nossas escolas, ainda hoje, revelam um modelo organizacional não muito diferente daquele. Por um lado, a "forma escolar moderna" viria a permitir maior acesso à cultura letrada e, em certos períodos históricos, maior democratização da educação. Todavia, os inconvenientes de uma escola de massas, potencialmente mais democrática, que, contudo, privilegiou o modelo de organização industrial, e por vezes militar - massificando a educação escolar e impondo sofisticados instrumentos

\footnotetext{
1.Universidade do Minho - Instituto de Educação - Departamento de Ciências Sociais da Educação - Braga, Portugal.

E-mail:1lima@ie.uminho.pt

2.Universidade Estadual de Campinas -Faculdade de Educação | Centro de Estudos Educação e Sociedade - Campinas (SP), Brasil. E-mail: ivanypino@gmail.com

3.Universidade Estadual de Campinas -Faculdade de Educação - Campinas (SP), Brasil. E-mail: adriaotheresa@gmail.com 4.Universidade Federal de São Carlos -Departamento de Teorias e Práticas Pedagógicas - São Carlos (SP), Brasil. E-mail: luana.ees@gmail.com

5.Centro de Estudos Educação e Sociedade - Campinas (SP), Brasil. E-mail: celsojoaoferretti@gmail.com

6.Universidade Federal de São Carlos -Departamento de Educação - São Carlos (SP), Brasil. E-mail: dazu@ufscar.br

7.Universidade de São Paulo -Faculdade de Educação - São Paulo (SP), Brasil. E-mail: sanzakia@usp.br

8.Universidade de Sorocaba - Sorocaba (SP), Brasil. E-mail: pedro.goergen@hotmail.com

9.Universidade de São Paulo -Faculdade de Educação - São Paulo (SP), Brasil. E-mail: moraescs@usp.br

10.Universidade Federal do Paraná - Setor de Educação - Curitiba (PR), Brasil. E-mail: adrianadragonesilveira@gmail.com

11.Universidade Federal do ABC - Centro de Engenharia, Modelagem e Ciências Sociais Aplicadas - São Bernardo do Campo (SP),

Brasil. E-mail: salomaoximenes@gmail.com

12.Universitat Autònoma de Barcelona - Barcelona, Espanha. E-mail: xavier.rambla@uab.cat
} 
de controle sobre professores, alunos e suas famílias -, são bem-conhecidos. De Paulo Freire (1987) e suas críticas à educação bancária e à escola burocrática e opressora até Ivan Illich (1977) e sua defesa de uma sociedade sem escolas, para que a educação, como processo de convivencialidade e de humanização, pudesse ocorrer, são inúmeras as queixas contra uma escola que, frequentemente, serviu a propósitos de desumanização, alienação e controle sobre corpos e mentes.

Illich acusou os professores de quererem transformar o mundo numa imensa sala de aula; ou seja, numa educação produtivista e em larga escala, que foi enclausurada numa sala, procurando, no entanto, generalizar esse modelo e expandi-lo universalmente, por meio da "maravilha tecnológica". Com efeito, os processos, diversos e contraditórios, de digitalização da educação escolar, de escola virtual, de desmaterialização da sala de aula, de educação dita "a distância", de cursos on-line, aí estão, presentes cada vez mais e com pujança, tendo, recentemente, beneficiado do estatuto de recurso emergencial no contexto pandémico da COVID-19.

Em situação de profunda crise em termos de saúde pública - deixando à vista o continuado desinvestimento em hospitais, escolas e instituições de educação superior públicos e, em geral, em vários sistemas de proteção social (crise essa políticamente aprofundada, no caso brasileiro, pelo Governo Federal, por meio do negacionismo e da priorização das questões econômicas sobre as sanitárias e sobre os direitos dos cidadãos) -, a digitalização da educação escolar foi considerada um mal menor por muitos de nós e, por outros, uma oportunidade com futuro.

Entretanto, trata-se de uma situação de emergência - em complemento ao ensino presencial e sob o comando desse último - ou de uma verdadeira alternativa em termos de provisão pública? Será possível circunscrever as ricas e pluriformes experiências sociais da educação escolar ao mundo digital e aos limites de um ecrã - mesmo se levarmos em consideração a atração crescente que os vídeos educativos, a produção de conteúdos, os jogos e toda uma vasta indústria de prestação de serviços em torno do "edutainment" (educação + entretenimento) vêm despertando, não só por parte de consumidores ávidos por experiências mais estimulantes, mas também, e sobretudo, por parte de grandes empresas multinacionais que produzem sistemas mercadorizados de ensino e aprendizagem (sistemas de franquia, kits de formação, materiais didáticos etc.)?

No Brasil, vastos são os estudos realizados sobre a mercantilização da educação por meio da comercialização de "sistemas privados de ensino" por grupos empresariais, inclusive transnacionais, para redes públicas de ensino, o que compele a destinação dos escassos fundos públicos para esses mercados, potencializados pela disseminação das plataformas digitais nesse quadro de pandemia.

Não se trata de diabolizar a tecnologia. A escola moderna sempre recorreu às tecnologias do seu tempo, que são interessantes recursos pedagógicos. O digital há muito entrou nas escolas, das plataformas eletrônicas de gestão aos materiais didáticos. No futuro, a discussão será em torno da inteligência artificial. A questão crucial reside em saber sob que objetivos, valores e interesses tais tecnologias serão usadas, sabendo-se que não existem tecnologias neutras. Ante a incerteza inerente à pandemia, como colocar as novas tecnologias da informação e comunicação a serviço de uma educação pública democrática? Serão possíveis combinações virtuosas, de tipo misto (b-learning), não socialmente discriminatórias? Que investimentos e formas de gestão públicos seriam exigíveis? Por que se tende a apresentar mais as exigências do lado do acesso a equipamentos informáticos e a redes de Internet (certamente indispensáveis), sobre as quais circulam grandes interesses comerciais, em detrimento dos avultados investimentos também necessários mesmo para modalidades capazes de combinar períodos de ensino presencial e a distância a todos os alunos? Num cenário pandémico, continuado ou intermitente, durante alguns anos, mais espaços pedagógicos, mobiliário 
e, especialmente, docentes seriam necessários para cumprir os quesitos de distanciamento social, em parques escolares frequentemente sobrelotados e degradados, com fracas condições de trabalho pedagógico.

O desafio de investimento será tanto mais expressivo quanto maiores forem as desigualdades e os processos de desresponsabilização estatal pela oferta educacional. No Brasil, os cortes orçamentários, a falta de investimento público e, consequentemente, a precarização do trabalho nos espaços escolares têm refletido desafios quase intransponíveis para o desenvolvimento consequente e socialmente comprometido da educação escolar. Demasiadamente desigual, a consolidação dos direitos sociais, entre os quais o educacional, tem sido cada vez menos universalizada em termos de acesso e qualidade de oferta, aspectos que, em contexto pandêmico, tornaram-se ainda mais agravados.

Mediada pelas desigualdades sociais, a maneira como o contexto de pandemia tem afetado as escolas e os sujeitos partícipes do processo acentua ainda mais a já desigual oferta educacional. A falta de acesso aos recursos digitais e às habilidades necessárias para seu uso; a sobrecarga de trabalho docente, com a introdução desses recursos; o custo pessoal dos envolvidos para sua implementação; a falta de tempo ou de condições objetivas dos estudantes e suas famílias para o acompanhamento das atividades propostas; e o sofrimento causado pelo isolamento social e por todo o contexto de risco à saúde e à vida são alguns dos aspectos que complexificam e questionam as respostas que vêm sendo dadas à questão.

Em qualquer um desses casos, mesmo admitindo cenários favoráveis em termos políticos e orçamentais, as questões de fundo, substantivas em termos educacionais, são outras. Não são apenas as questões decisivas que interrogam velhas e novas desigualdades sociais, econômicas e culturais desigualdades essas que não se vê como possam ser ultrapassadas por uma escola virtual, não sendo, em vez disso, difícil imaginar que possam sair reforçadas pelo uso de tecnologias só aparentemente democráticas e acessíveis a todos os públicos.

A questão magna reside em saber, como sempre, o que entendemos por educação democrática como processo de humanização dos seres humanos e se ela é atingível fora de um contacto humano e presencial prolongado, típico de todos os processos de socialização secundária existentes em um ambiente educativo multicultural, de socialização entre os pares e de trabalho cooperativo e solidário - em suma, de vida escolar, convívio e diálogo e de formação não apenas académica e passível de mensuração em contextos concorrenciais e de produção de imagens escolares competitivas, mas, especialmente, de formação sócio moral e ético-política, desenvolvimento pessoal e social de crianças e jovens, para muito além de sua "alunização" restrita.

Se o campo educativo escolar resistir à sua transformação em subcampo comercial, de acordo com os impulsos do vocacionalismo, do empreendedorismo e da empregabilidade - sob comando das ideologias meritocráticas e reelitizadoras -, então será oportuno começar por afirmarmos com clareza, daí retirando as devidas consequências, que não há vida escolar on-line e que o ideal de uma educação escolar e integral dos seres humanos, para muito além da constituição de "capital humano", resulta de um trabalho lento e artesanal, não da cultura do imediatismo e do instantâneo, de que falava criticamente Zygmunt Bauman (2001).

Exige não confundir acesso à informação on-line com educação, já que essa última implica docentes e alunos, entre outros sujeitos, uma ação social prolongada, convívio e conhecimento mútuo e relações face a face, num entorno que é muito mais do que um simples contexto, antes constituindo um ator educativo e cultural complexo e heterogéneo. 


\section{Referências}

BAUMAN, Z. Modernidade líquida. Rio de Janeiro: Jorge Zahar Editor, 2001.

COMÉNIO, J. A. Didáctica magna: Tratado da arte universal de ensinar tudo a todos. Lisboa: Fundação Calouste Gulbenkian, 1976.

FREIRE, P. Pedagogia do oprimido, 17. ed. Rio de Janeiro: Paz e Terra, 1987.

ILLICH, I. Sociedade sem escolas. Petrópolis: Vozes, 1977.

Recebido: 10 jul. 2020

Aceito: 10 jul. 2020 